\title{
Özgeci Davranışın Sosyal İnovasyona Etkisi: Teknoloji Sektöründe Bir Araştırma
}

\section{The Effect of Altruistic Behaviour on Social Innovation: \\ A Research in the Technology Sector}

\author{
Saadet Ela PELENK, Recep Tayyip Erdoğan Üniversitesi, Türkiye, epelenk503@gmail.com \\ Orcid No: 0000-0002-8068-5518
}

\begin{abstract}
Öz: Toplumsal dengeyi ve düzeni sağlayan sosyal inovasyon, bu eylemi gerçekleştirecek kurumlar, aktörler, girişimciler ve paydaşların etkin katılımılla mümkündür. Insan, doğası gereği sosyal ve iletişime ihtiyaç duyan bir varlıktır. İnsan gruplarından oluşan toplumun, kuşkusuz ihtiyaçlarl ve problemleri vardır. Bu problemlerin çözümünde işletmeler, gönüllü kuruluşlar ve devlet katkalarını sağlar. Iş̧letmeler ve çalışanları, gerek sosyal sorumluluk projeleri gerekse sistematik değişim öncüsü olarak toplumun ihtiyaçlarını karşılamaktadır. Bu noktada işletmelerin beşeri kaynağl olan çalışanların kuşkusuz büyük payı ve önemi vardır. Çalışanların sahip olduğu hangi özellikler, onları sosyal inovasyona yönlendirmektedir? Özgecilik, başkalarına gönüllü olarak yardım edebilme, duyarlı olma, öngörü ve sorumluluk sahibi olmaktır. Çalışanların özgeci davranışları, sosyal inovasyon faaliyetlerini besleyebilir mi? sorusu araștırmanın problemini olușturmaktadır. Araştırmanın amacı teknoloji alanında özgeci davranıșın, sosyal inovasyona etkisini incelemektir. Bu doğrultuda araştırma örneklemini, Istanbul ve çevresinde faaliyet gösteren teknoloji işletmelerinin 200 çalışanı oluşturmaktadır. Anket yönteminden yararlanılarak elde edilen veriler, korelasyon ve regresyon analizleriyle çözümlenmiştir. Araştırma sonucunda, teknoloji sektöründe özgeci davranışların sosyal inovasyonu pozitif ve anlamlı olarak etkilediği tespit edilmiştir.
\end{abstract}

Anahtar Sözcükler: Özgecilik, Sosyal İnovasyon, Teknoloji, İnovasyon.

Abstract: Social innovation, which ensures social balance and order, is only possible with the active participation of the institutions, actors, entrepreneurs and stakeholders that will carry out this action. Human is an intrinsically social being and needs communication. A society of human groups undoubtedly has needs and problems. In order to solve these problems businesses, voluntary organizations and government provide their contributions. Businesses and their employees meet the needs of society both as a pioneer of social responsibility projects and a systematic change. At this point, employees, the human resources of enterprises, undoubtedly have a large share and are of great importance. What features of employees lead them to social innovation? Altruism is to help others voluntarily, to be sensitive, to have foresight and responsibility. The question of "Can altruistic behaviors of employees foster social innovation activities?" is the problem of the research. The aim of the research is to examine the effect of altruistic behavior in the field of technology on social innovation. Accordingly, the research sample consists of 200 employees of technology enterprises which operating in and around Istanbul. The datas which obtained from survey method were analysed by correlation and regression analyzes. As a result of the research, it was determined that altruistic behaviours in the technology sector, positively and significantly effect the social innovation.

Keywords: Altruism, Social Innovation, Technology, Innovation

\section{Giriş}

21. Yüzyıl işletmelerinin varlıklarını devam ettirebilmeleri için, yenilikçi ürün ve hizmetler ortaya koymaları gerekli hale gelmiştir. Diğer yandan son y1llarda artan toplumsal problemlerin çözümüne yönelik, toplumun bir parçası olan işletmelere büyük sorumluluklar düşmektedir. Bu nedenle işletmeler, eskiye oranla sosyal sorumluluk projelerinde daha çok yer almaktadırlar. Sosyal açıdan özgecilik, yardımlaşma eylemi ile toplumun ahlaki, kültürel ve ekonomik yapısında önemli bir bileşendir.

Sosyal inovasyon, yaratıcı fikir, hayal gücü, sebat etmek ve risk alarak bir ürün ya da hizmetin geliştirilmesi, ardından katılımcı bir süreç izlenmesi ve güçlü ortaklıklar kurularak ölçeklendirilmesidir (Hubert, 2010). İnovasyonun sistemsel boyutu olan sosyal inovasyon, çalışanların yardımlaşma ve gönüllülük esasına dayanır. Özel ya da kamu işletme çalışanlarının, bir problemin çözümüne farklı ve etkin çözüm sağlamaları, sosyal yenilikçiliğin temel unsurudur. Araştırmanın amacı, teknoloji şirketlerinde özgeciliğin (alturism), sosyal inovasyona etkisini incelemektir. Bu amaçla İstanbul ve çevresinde faaliyet gösteren ve teknoloji-bilişim-telekomünikasyon alanında çalışan 200 kişi ile anket çalışması yapılmışıtır. Araştırma örnekleminin teknoloji işletmelerinden seçilme nedeni, Schumpeter'ın (1934) belirttiği gibi "teknolojik yenilikçilik ve ekonomik etkinliğin sağlanmasında sosyal inovasyonun gerekli bir unsur" olduğudur. Toplumu geliştiren ve düzenleyen sosyal inovasyon için,işletmeler önemli bir aktördür. İşletmelerin faaliyet ve projelerinin başarısı etkin, öngörülü, aktif ve duyarlı çalışanlarına bağlıdır. Özgecilik (Mair ve Marti 2006) ve bu davranış ile sağlanan sosyal yarar (Fowler, 2000), sosyal inovasyonu güçlendirebilir. Çalışanlar, yardım etmekten motive olmak ya da başarı ihtiyacı için sosyal inovasyona yönelebilirler (McClelland 1967).

$\mathrm{Bu}$ çalışma, sektöre göre değişebilmekle birlikte, sosyal inovasyon için gerekli olduğunu tahmin edilen örgütsel vatandaşlık boyutlarından özgeciliğin, sosyal inovasyona etkisini incelenmiştir. Literatürde özgeciliğin, sosyal inovasyon etkisini ele alan çalışma sayısının az olduğu (Yeşilkaya ve Yıldız 2018) ve ülkemizde gönüllülük esasına dayalı inovatif 
faaliyetlerin, "sadece işletmenin başarısı değil, ülkenin kalkınması ve imajını” önemli derecede etkilemesi çalışmanın katkısını ve yapılma nedenini oluşturmaktadır. Sosyal inovasyon, içinde bulunulan toplumun problemleri ve yapısı ile yerel olarak biçimlenerek, ülkeden ülkeye farklılık arz etmektedir. Araştırma örneklemi, teknoloji sektöründe çalışanlardan seçilmiştir. Teknoloji-telekomünikasyon işletmeleri, inovasyonu en çok uygulayan ve sosyal sorumluluk projelerini yürüten kuruluşlardır. $\mathrm{Bu}$ araştırma, teknoloji- telekomünikasyon sektöründe çalışanların, toplumsal problemlere duyarlılıklarını, özgeci davranış açısından değerlendirerek; yöneticilere, çalışanlara, akademisyenlere ve konu ile ilgili diğer kişilere bilgi vermeyi ve farkındalık kazandırmayı amaçlamaktadır.

Özgeciliğin, sosyal inovasyon açısından incelendiği bu araştırma giriş bölümü; özgecilik ve sosyal inovasyon tanımları, süreci, etkileri ve bu değişkenler arası ilişkileri içeren kavramsal bölüm; veri toplama aracı, ölçekler ve analiz yöntemini içeren araştırma yöntemi bölümü; demografik özelliklere ilişkin bilgiler ve araştırma sorunsalının çözümüne yönelik hipotezlerin sınanmasını içeren bulgular ve tartışma-sonuç-önerilerin yer aldığı beş bölümden oluşmaktadır.

\section{Kavramsal Çerçeve}

\section{1. Özgecilik}

Özgecilik (altruism), pozitivizmin kurucusu olan Comte (1986) tarafından literatüre kazandırılmış bir kavramdır. Comte (1986) özgeciliğin, bencillikten uzak insani bir meseleyi ilgilendirdiğinden bahsederek, manevi birliği sağlayıcı etkisine vurgu yapmıştır. Bu bağlamda özgeciliğin, "başkası için yaşamak” adına din ile ilişkisine değinmiştir.

Özgecilik, ben merkezden uzak ve fedakâr davranarak başkası yararına gönüllü hareket etmektir (Frey ve Meier 2004; Taylor, Peplau ve Sears 2010). İş yaşamında özgecilik, bir çalışanın yardım eylemini, benimsediği norm ve prensipler ile bütünleştirmesine dayanır (Carlo ve Randall 2002). Dolayısıyla özgeci davranış, çalışan tarafından benimsenen bir eylem olup, ödül ya da ceza beklentisi ile yapılmaz (Chou 1996). Çalışan özgeci bir düşünce sahipse, tüm bireylere fayda ve katkı sağlayacağı bir sinerjiye inanır (Morrison ve Severino 2007) ki bu durumda özgeci davranış, bireysel boyuttan takımsal boyuta kayabilir. Dolayısıyla bireysel olarak başlatılan faydacı bir davranış ve yardım duygusu, işbirliği ilişkisi içinde devam ettirilir (Bilgin 1988; Fakouri, Fakouri ve Zucker 1991).

Andreoni’ye (1990) göre özgeci davranış, bireyin toplumdaki saygınlığını arttırmak için de yapılabilir. Bu bağlamda kişi göz önünde olarak, yeni iş imkânlarına kavuşabilir (Harbaugh 1998).Penner'e göre (1978) özgeci davranış, sosyal normlar çerçevesinde şekillenir ki toplum, sosyal normları üyelerine aktarır. Sosyal norm, üyenin sergilemesi gereken davranış hakkındaki toplumun beklentisi olup, sosyal sorumluluk ve karşılıklı yardım sosyal normun iki türünü oluşturur. Bir bakıma toplum, kişi ve işletmelerden yardım ve duyarlılığı beklemektedir. Mair ve Marti (2006) özgeci davranışın, sosyal girişimciliğin bir yansıması olduğunu belirtmektedir. Bu girişimciler hem topluma fayda sağlamakta hem de bu eylemden motive olmaktadırlar.

Folger, Cropanzano, Greenberg ve Cropanzano (2001), özgeciliği ahlaki temellere dayandırarak açıklamıştır. Bu düşünceye göre özgecilik, bireyin üst sistem olan toplumun bir parçası olarak diğer insanlara âdil şekilde yardım etmesidir. Ancak bu yardım duygusu, doğuştan değil, tecrübeler ile öğrenilerek kazanılabilir (Akbaba 1994). Sosyal öğrenme teorisine göre birey, çevresi ile sürekli etkileşim halinde olup, çevresinden etkilenir ve öğrenir (Bandura ve Mc Clelland 1977). Sosyal öğrenme kuramına göre birey, sosyalleşme sürecinin sonucu olarak özgeci davranmaktadır. Dolayısıyla birey, yardım ve paylaşmak ile model davranışları gözlemleyerek kazanmaktadır (Mussen ve Eisebergberg 1977). Batson'a göre (2010) özgecilik, psikolojik temellere dayalıdır ve bireylerin karşı tarafi anlama becerisine (empati yeteneğine) bağlı olarak gelişir. Bu bağlamda özgeci davranış, empati yeteneği (Walter ve Finley 1999), güven ve sorumluluk duyguları ile ilişkilendirilebilir (Fakouri 1991).

Freedman, Sears ve Carlsmith'e (1976) göre özgeciliğin, olumlu bir davranışla sonuçlanması sorumluluk duygusu ile doğru orantılı gelişmektedir. Bu bağlamda kişinin sorumlu olduğunu hissetmesi sağlanarak, yardım etme eylemi arttırılabilir. Eğer bir ihtiyaç ya da yardım isteği belirgin ise kişi, diğer insanların varlığını etkisiz kabul ederek ihtiyaç talep edene yardım edebilmektedir.

Özgeci davranan çalışan, toplumsal değer oluşturmak ve sürdürmek adına değişim ajanı görevi üstlenmektedir.Bu noktada çalışanlar, sosyal inovasyon için, bir misyona hizmet edecek yeni firsatları tanır ve takip eder, inovasyon uyum ve öğrenme sürecine katılır, mevcut kaynakları cesaretle değerlendirir ve sonuçlar hakkında tahminleme yapar (Dees 2001).

\subsection{Sosyal İnovasyon}

Sosyal inovasyon finansal, ekonomik, sosyal ve çevresel problemlere çözüm üretmek, çözüm sürecinde işbirliğini arttırmak için girişimcilerin aktif katılımıyla oluşan inovasyon türüdür (Klein vd. 2012). Ancak sosyal girişimciler ve çalışanlar, uyumsuz denetim veya düzenleyici kültüre bağlı olarak birtakım engeller ile karşılaşabilirler. Bu zorluklar finans,yönetim, yetenek ve sosyal inovasyon ölçümleri ile ilgili olabilir. Özellikle finansman açısından sosyal inovasyonun gelişimi aşamasında yer alan süreçlerde, sektörde çalışan bireyler ve kuruluşlar tarafindan gerekli desteğin sağlanmasında yetersizlikler olabilir. Diğer yandan sektörler arası ve sosyal inovasyon sürecinin tüm aşamalarında bu tür problemler, yetenek, ilgi ve paylaşım unsurlarıyla çözülebilir (Hubert 2010). Şekil 1'de sosyal inovasyon için girişimlerin finansmana erişim engelleri yer almaktadır: 


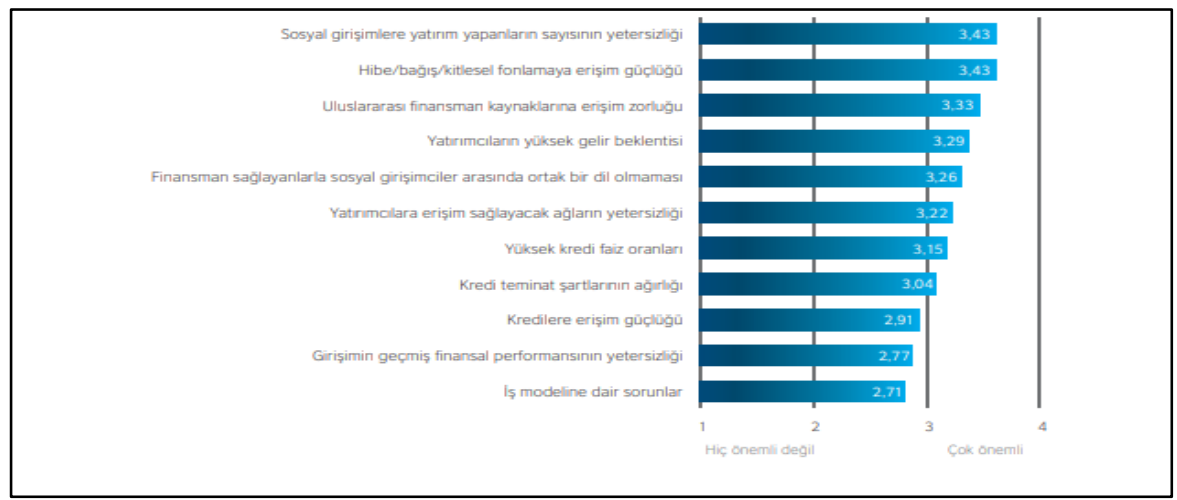

Şekil 1. Girişimlerin Finansmana Erişim Engelleri Kaynak: British Council Report, Türkiye, 2019.

Light'e göre (2005) sosyal bir girişimci, sosyal problemlere yaratıcı fikirleri ile çözüm arayan birey, grup ya da örgüt birliği olup, yaratıcılık ve sürekli değişimi esas kabul etmektedir. Sosyal inovasyonun mimarları olan sosyal girişimciler, yenilikçilik (inovasyon), vizyonerlik, değer yaratmak, sosyal amaçları öncelikli tutmak, sosyal sorunlara yenilikçi çözüm sağlamak, sosyal ihtiyaç algısına sahip olup, bu ihtiyaçları gidermek gibi temel özelliklere sahiptirler. Bu bağlamda sosyal inovasyon ile girişimciler riskli olsa bile kâr elde edebilir, toplumu değişime adapte edebilir, az kullanılan kaynakları değerlendirerek toplumsal ihtiyaçların çözümüne dikkat çekebilirler (Thompson, Lees ve Alvy 2000; Glancey ve McQuaid 2000; Haugh 2005; Mair ve Marti 2006). Sosyal inovasyonun temel (çekirdek) unsurları ve sosyal inovasyona genel bakış açısı Şekil 2'deki gibidir:

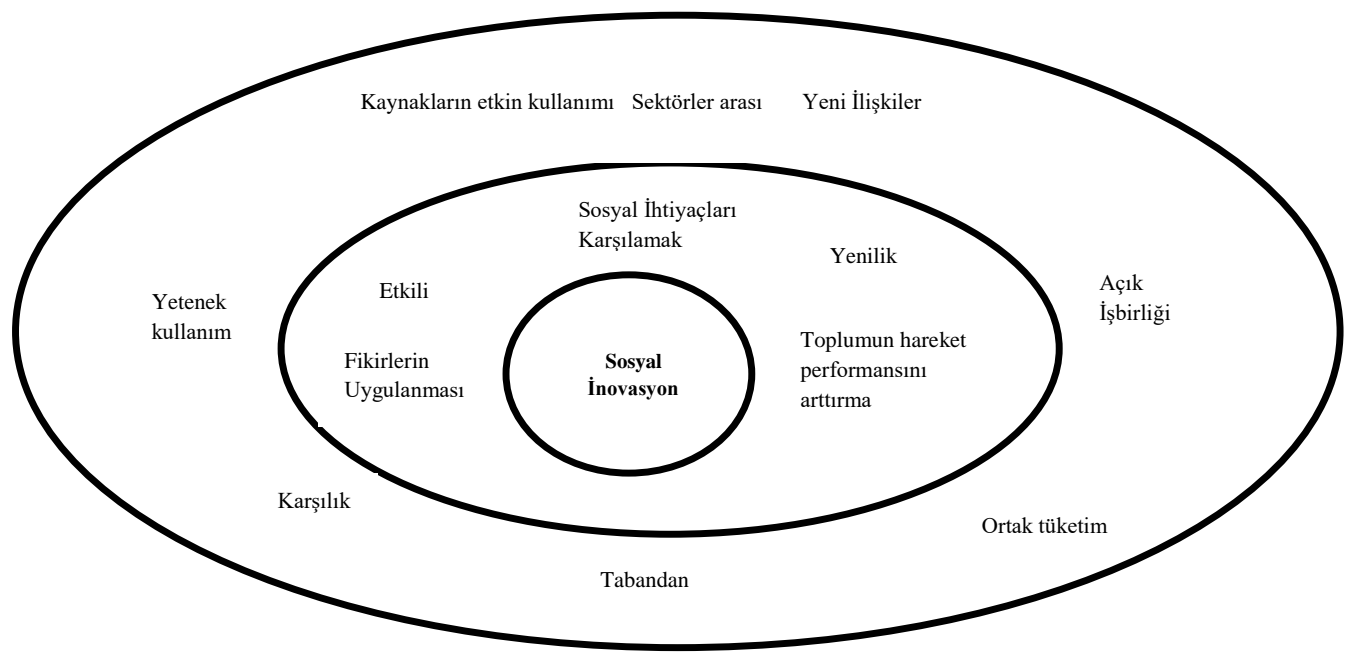

Şekil 2. Sosyal İnovasyonun Temel Unsurları

Schwartz'a göre (1993) sosyal inovasyon, pozitif sosyal davranış başlı̆̆ı altında değerlendirilebilir. Sosyal inovasyon kavramı, 1990'larda popülerlik kazanmış ve uygulama olarak geniş bir alana yayılmıştır. Sosyal inovasyon türleri Tablo 1'deki gibidir:

Tablo 1. Sosyal İnovasyon Türleri

\begin{tabular}{|l|l|l|}
\hline Sosyal İnovasyon Türleri & Tanımlar & Örnekler \\
\hline Yeni Hizmet ve Ürünler & $\begin{array}{l}\text { Sosyal ihtiyaçlarını karşılayacak yeni } \\
\text { müdahaleler ve programlar }\end{array}$ & $\begin{array}{l}\text { Araç paylaşımı } \\
\text { Sıfır enerji konutlarının gelişimi }\end{array}$ \\
\hline Yeni Uygulamalar & $\begin{array}{l}\text { Yeni profesyonel ilişkileri gerektiren } \\
\text { hizmetler }\end{array}$ & $\begin{array}{l}\text { Vatandaşlar arasında } \\
\text { anlaşmazlıkların çözümü }\end{array}$ \\
\hline Yeni Süreçler & Yeni hizmetlerin ortak üretimi & $\begin{array}{l}\text { Katlımıı bütçeleme } \\
\text { Ticaret fuarı }\end{array}$ \\
\hline Yeni Kural ve Düzenlemeler & $\begin{array}{l}\text { Yeni kanun ve yönetmeliklerin } \\
\text { oluşturulması }\end{array}$ & Kişisel bütçeler \\
\hline
\end{tabular}

Kaynak:TEPSIE(2014).Building the Social Innovation Ecosystem.A Deliverable of the Project: "The Theoratical , Empirical and Policy Foundations for Building Social Innovation in Europe (TEPSIE)'”European Commission-7th Framework Programme, Brussels: European Commission'dan aktaran Öztürk,2016:13. 
Sosyal inovasyon ürün, üretim süreci, teknoloji, bir ilke, toplumsal eylem ve müdahalenin birleşimi sayılabilir (Hubert 2010'dan aktaran Öztürk 2016). Bu amaçla sosyal bir ihtiyaç, ancak farklı nitelikteki çalışanların ve diğer kaynakların verimli kullanılması ile çözülebilir. İşletmeler ve diğer girişimcilerin,sosyal bir ihtiyaca cevap verebilme ve toplumsal bir probleme etkin çözümler üretebilmesi toplumun gelişimini ve hareket kabiliyetini hızlandıracaktır. Sosyal inovasyonun etkinliği sekiz temel özelliğge bağlıdır (Caulier-Grice vd. 2012):

1-Sosyal inovasyon, çeşitli sektörler ya da sektörler arası oluşabilir, taşınabilir ya da farklı ara kesitlerde belirebilir.

2-Sosyal inovasyon, çalışanlar ve bireyler arası işbirliğini gerektirir. Bu bir bakıma çalışanların geniş katılımı olarak yorumlanabilir.

3-Sosyal inovasyon yerelden ve tabandan tavana gider. Öncelikle yerel bir ihtiyaç ve probleme etkin bir çözüm bulmayı hedefler.

4-Üretici ve tüketici sınırları daha az tanımlanmıştır. Bu bağlamda kişiler, ürün ve hizmetleri sadece alan pozisyonunda değildirler.

5-Biyolojik olarak mutualist bir ilişki söz konusudur. Karşılıklı yararlanma olarak nitelendirilen mutualizm, sosyal inovasyon açısından, bireysel ve toplumsal refahın ancak karşılıklı bağımlı bir ilişki ile elde edileceğini ileri sürer.

6-Sosyal inovasyonu kullananlar ve yararlananlar, yeni rol ve sorumluluklara sahiptirler.

7-Sosyal inovasyon, kaynakların etkin kullanımını gerektirir.

8-Uzun sürede, yararlanıcıların ihtiyaçlarını karşılayarak, yeteneklerini geliştirir.

Sosyal inovasyon, "biçimselleştirme, değişim süreci ve sosyal sonuçlar” olarak üç boyutta değerlendirilmiştir (Choi ve Majumdar 2015). Biçimselleştirme boyutu, toplumsal inovasyonun farklı şekillerde ve bileşimlerde (iş modeli, teknik bir hizmet, üretim süreci vb.) ortaya çıktığını vurgular. Değişim süreci boyutu, sosyal inovasyonun sosyal yapılarda yarattığı değişimin nedenini ifade eder. Sosyal sonuçlar boyutu ise, sosyal hedef ve ihtiyaçları tanımlayan boyut olup, uygulamada yapılan değişiklikler ile toplumsal değeri ortaya koyar.

Hubert'e göre (2010) sosyal inovasyon, "toplumsal talep perspektifi, toplumsal mücadele ve sistematik değişiklikler perspektifi” olarak üç boyuta ayrılmaktadır. Toplumsal talep perspektifi, sosyal inovasyonun tamamlayıcı unsurunu ekonomik boyut olarak görmektedir. Toplumun daha az güçlü ya da az yarar sağlayan kesimlerin ihtiyaçlarına ağırlık verilir. Sosyal yenilikçilik, toplumsal talep perspektifi boyutunda önemli roldedir. Sosyal yenilikçiler, işbirliği ve değişim ağları vasıtasıyla yeni yaklaşımları benimser, belirsizliklerin ve değişime direncin üstesinden gelirler. Sosyal yenilikçiler, işbirliği ve değişim ağları ile ekonomik faaliyetler, mal ve hizmet üretimi, sağlık ve eğitim hizmetleri, çocuk ve yaşlı bakımı, toplumun gelişime olanak sağlayan diğer hedefleri gerçekleştirirler. Toplumsal mücadele perspektifi boyutu, sürdürülebilir kalkınma ile ilgilenir ki; inovasyon, toplumsal sorunların çözümü ve toplum refahı için bir araç olarak kullanılır. Sistematik değişiklikler perspektifi boyutu, işletmeler ve paydaş ilişsisinde kurumsal değişisme kadar uzanan sürdürülebilir sistematik değişime odaklanır. Sistematik değişiklikler güçlendirme, sürekli öğrenme ve iletişim-ağ yapıları merkezi olup, sonuçları çalışanların yöntemleriyle yeniden şekillenir. Dolayısıyla sosyal inovasyon, çalışanların tutum ve değerleri, işletme stratejileri, politikaları, kültürü, örgütsel yapılar ve süreçler, iletişim kanalları, işletmenin misyonu ve sorumlulukları, aktörler (sosyal yenilikçiler, girişimciler) arasındaki iletişim değişikliklerini içerir.

Türkiye'de sosyal inovasyon örnekleri giderek artmakta olup; Toplum Gönüllüleri Vakfı (TOG), Genç Bank Programı, Usturlab Genç ve Çocuk Atölyeleri, Genç Gönüllüler Platformu, üniversitelerde kurulan sosyal girişimcilik programları, laboratuvarlar vb. başlatılan bir takım sosyal inovasyon programlarıdır (Ateş, 2018).

\subsection{Değişkenler Arası İlişkiler ve Hipotez Geliştirme}

Markman ve Baron (2003), kişinin kendisine yanlış gözüken bir durumu düzeltmeye çalışması, zor durumların azimle üstesinden gelmeye çalışması, hedef ve amaca ulaşmadaki kararlılığı olan sebatkarlığın sosyal inovasyonu olumlu etkilediğini tespit etmiştir. Sosyal inovasyon için çalışanların azimli ve kararlı olmaları ile birlikte ihtiyaç sahiplerine duyarlı olmaları da (özgecilik) önemlidir (Mair ve Marti, 2006).

Kasapoğlu (2013), iyilik hâli ve özgecilik ilişkisini üniversite öğrencileri üzerinde incelemiştir.İlgili araştırma sonucunda,iyilik hali ve özgecilik ilişkisi özellikle son sınıf öğrencilerinde pozitif yönlü ve anlamlı çıkmıştır ve sosyal çevrelere göre farklılık göstermiştir.

Köksal, Gürsoy ve Yapar (2018), özgeciliğin çalışan performansına etkisini, kamu sektöründe incelemişlerdir.İlgili çalışma sonucunda özgeci davranışların, çalışanların iş performansını olumlu olarak etkilediği tespit edilmiştir. Çiftçi ve Gürer (2019),özgeciliğin çalışan performansına etkisinde çalışan sesliliğinin aracı rolünü incelemiştir.Araştırma sonuçlarından biri özgeci davranışın, çalışanın kapasitesi ortaya koyabilmesinde çalışan sesliliğinin aracı rol oynamasıdır.

Kümbül Güler (2008) doktora tezi çalışmasında, sosyal inovasyon ile eş anlamlı kullanılan diğer yandan sosyal inovasyonu etkileyen sosyal girişimcilerin özelliklerini tespit etmiştir. İlgili çalışmada sosyal girişimcilerin yaratıcı, mücadeleci,özgüvenli, özgeci, sosyal,maneviyata ve toplumsal dayanışmayı önemli adleden kişiler oldukları, ayrıca bu çalışanların güç aralığından olumsuz etkilenen ve bireysel başarı unsurlarından pozitif etkilendikleri tespit edilmiştir.

Keleş ve Özkan (2018), Ankara ilinde yer alan çevreci sivil toplum kuruluşu çalışanlarının sosyal sorumluluk ve özgecilik tutumlarını incelemişlerdir. İlgili çalışma sonucunda, bu kuruluşlarda çalışanların özgeci davranışlarının yüksek olduğu tespit edilmiştir. 
Jurik ve Bodin'in (2014) yetmiş üç adet küçük ve orta ölçekli, içerisinde yazılım ve teknoloji firmalarının da yer aldığı çalışmasında, sosyal konuda yapılan eylemler için (sosyal sorumluluk projeleri vb.), çalışanların positif bir sosyal değişime ihtiyaç duydukları ve özgeci olmalarının önemi vurgulanmıştır.

Yıldırım ve Topçuoğlu (2016), özgeciliği demografik faktörler açısından incelemiştir. İlgili çalışmada özgeciliğin, çalışanların cinsiyet ve sosyo ekonomik düzeye göre farklılaşmadığını tespit edilmiştir. Yöntem ve İlhan (2013), toplulukçu değerler söz konusu olduğunda, bireyci benlik kurgusunun özgecilik üzerindeki etkisinin anlamsılaş̧ı̆̆ını tespit etmiş̧tir. Bir bakıma toplumsal ihtiyaç ve beklentiler arttıkça kişiler, empati kurarak bireysel düşünceden kolektivist düşünce ve algılamaya kaymaktadır.

Ateş (2018), Türkiye'deki sosyal inovasyon uygulamaları ve sosyal inovatif çalışmaları genç nüfusun potansiyeli açısından incelemiştir.İlgili çalışmada, dijital sosyal inovasyon ile gençlerin ihtiyaçlarına dönük yenilikçi platformların sayısı her geçen gün arttığı vurgulanmıştır. Gençlerin, sosyal inovasyon konusunda girişimci ve hevesli olduğu ancak yeterince desteklenmediği belirtilmiştir. Dolayısıyla gençlerin politik ve sivil alanlarda kendilerini ilgilendiren süreçlere katılım imkanlarını artırmak için yeni çözümler sunulması önemli görülmüştür.

Fowler ve Kam (2007), özgeciliğin ve sosyal kimliğin kişilerde katılımcılığı (politik) arttırdığını tespit etmişlerdir. Sorokin (1948) özgeciliği, sosyal problemlerin çözümünde önemli bir etken olarak ifade etmiştir. Hubert (2010),sosyal inovasyonu çalışanların güçlendirilmesi, katılımcılığı, çok yönlü iletişim ağlarını kullanabilme yetenekleri, işletme yapısı ve stratejisiyle ilişkilendirmiștir.

Yeşilkaya ve Yıldız (2018) özgeci davranışın sosyal inovasyon eğilimine etkisini inceledikleri çalışmada özgeci davranışın, sosyal inovasyona pozitif ve anlamlı etkisini tespit etmişlerdir. Literatürde yer alan çalışmalardan yola çıkarak şekil 3'deki araştırma modeli ve $\mathrm{H}_{1}$ hipotezi geliştirilmiştir.

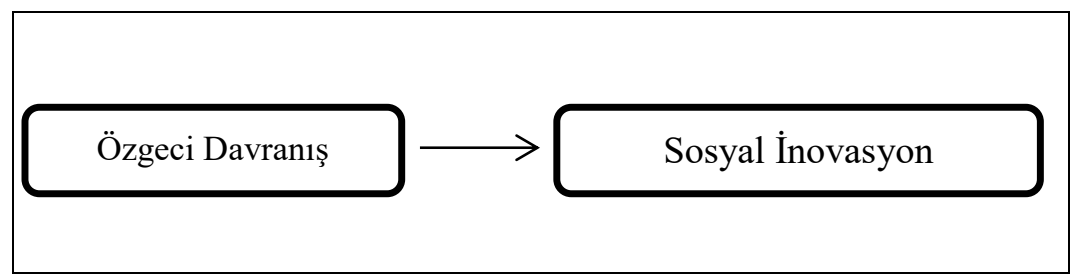

Şekil 3. Araştırma Modeli

Araştırma modelinden hareketle $\mathrm{H}_{1}$ hipotezi oluşturulmuştur:

$\mathbf{H}_{\mathbf{1}}=$ Teknoloji işletmelerinde çalışanların özgeci davranışı, sosyal inovasyonu pozitif ve anlamlı olarak etkilemektedir.

\section{Araştırma Yöntemi}

\subsection{Veri Toplama Yöntemi ve Ölçekler}

Araştırma evrenini İstanbul ve çevresinde basın-medya araçları ile yenilikçi görüş ve uygulamalarını açıklayan teknoloji alanındaki büyük ölçekli işletmelerin 300 çalışanı oluşturmaktadır. Ancak katılımcılara gönderilen 300 anketten geri dönüş yapılan ve hatalı olanlar çıkarıldıktan sonra kalan 200 anket analize dâhil edilmiştir. Araştırmada kolayda örnekleme yöntemi kullanılmıştır.

Anket, yapısal olarak "demografik, özgecilik ve sosyal inovasyon" ile ilgili soruları içeren üç kısımdan oluşmaktadır. Anketin demografik olan birinci kısmında katılımcıların cinsiyet, eğitim bilgileri ve medeni halleri ile ilgili sorular yer almıştır. Anketin ikinci kısmında sosyal inovasyonu ölçmek üzere, Yeşilkaya ve Yıldız'ın (2018) çalışmasında yer alan Bulut, Eren ve Halaç'ın (2014) dokuz sorudan oluşan sosyal inovasyon ölçeği kullanılmıştır. Sosyal inovasyon ölçeği, tek boyuttan oluşmaktadır. Anketin üçüncü kısmında, özgeciliği ölçmek üzere yirmi maddeden ve tek boyuttan oluşan Rushton, Chrisjohn ve Fekken'in (1981) özgecilik ölçeği kullanılmıştır. Anket, en olumlu cevaptan en olumsuz cevaba doğru sıralanan 5'li likert ölçme sistemine göre oluşturulmuştur (5=Kesinlikle katılıyorum, 1=Kesinlikle katılmıyorum).

\subsection{Veri Analizi}

Araştırma verilerinin analizinde SPSS 23.0 istatistik programından yararlanılmıştır. Araştırma ölçeğinin güvenilirliğini test etmek amacıyla Cronbach Alpha ile iç tutarlık analizi uygulanmıştır. Araştırmanın değişkenlerinin ortalama, standart sapma ve normallik dağılımları tespit edilmiştir. Özgecilik ve sosyal inovasyona ait puanlar yüksek düzeyde negatif çarpıklık (skewness) gösterdiğinden yansıtma-logaritmik dönüşüm işlemi yapılmıştır.

Araştırma verilerini analiz etmek için öncelikle ölçeklerin güvenilirlikleri test edilmiştir. Sosyal inovasyon ölçeğinin Cronbach Alfa değeri 0,87 olarak tespit edilmiştir. Özgecilik ölçeğinin Cronbach Alfa değeri 0,81 olarak ölçülmüştür $(\alpha \geq 0,70)$. 
Ölçeklerin faktör yükleri dağılımları incelenmeden önce Kaiser Meyer Olkin ve Barlett Testleri yapılmıştır $(\mathrm{KMO}=$ $0,86 ; \mathrm{p}=0,00)$. Sosyal inovasyon ölçeğinin dokuz maddesi tek boyut altında toplanmış olup, faktör yükleri 0,78 ile 0,54 arasında yer almaktadır. Özgecilik ölçeğinin faktör yükleri dağılımı, 0,77 ve 0,58 aralığında yer alıp, tek faktör altında toplanmıştır.

Araştırma hipotezlerinin test etmek amacı ile basit doğrusal regresyon analizi yapılmış olup, bu analiz öncesinde değişkenler arası ilişkiyi tespit etmek için korelasyon analizi uygulanmıştır. Değişkenlerin korelasyon katsayıları, pozitif ve anlamlı çıkmıştır. Araştırmada tek bir bağımsız değişken olan özgeciliğin, bağımlı değişken olan sosyal inovasyona etkisi incelendiğinden basit doğrusal regresyon analizinden faydalanılmıştır.

\section{Bulgular}

\section{1. Demografik Özelliklere İlişkin Bulgular}

Anketten elde edilen veriler, demografik açıdan incelendiğinde ankete katılan 200 kişinin \%60’1 erkek (120 kişi), 80 kişi ise kadın katılımcılardan oluşmaktadır. Katılımcıların \%70’i (140 kişi) lisans mezunudur. Katılımcıların \%20'si yüksek lisans (40 kişi) ve \%10’u doktora (20 kişi) derecelerine sahiptir. Katılımcıların \%80’i evlidir (160 kişi).

\subsection{Araştırma Sorunsalının Çözümlenmesi}

\subsubsection{Betimsel İstatistikler ve Korelasyon Analizi}

Araştırma ölçeklerinin faktör analizi, güvenilirlik testleri ve korelasyon analizi yapılmıştır. Araştırma değişkenlerinin ortalama, standart sapma değerleri ile güvenilirlik katsayıları Tablo 2’de gösterilmiştir.

Tablo 2. Değişkenlerin Betimsel İstatistikleri ve Güvenilirlik Katsayıları

\begin{tabular}{|l|l|l|l|l|l|c|c|c|}
\hline & $\begin{array}{l}\text { Madde } \\
\text { Sayıs1 }\end{array}$ & Ortalama & Mod & Medyan & $\begin{array}{l}\text { Standart } \\
\text { Sapma }\end{array}$ & Güvenirlik & Çarpıklık & $\begin{array}{l}\text { Kolmogorov- } \\
\text { Simirnov(p) }\end{array}$ \\
\hline Özgecilik & 20 & 4,09 & 4,35 & 4,15 & 0,49 & 0,81 & $-0,820^{\mathrm{a}}$ & 0,00 \\
\hline Sosyal İnv. & 9 & 4,13 & 4,56 & 4,22 & 0,56 & 0,87 & $-0,560^{\mathrm{b}}$ & 0,00 \\
\hline
\end{tabular}

${ }^{\mathrm{a}, \mathrm{b}}$ Logaritmik dönüşüm

Tablo 2'de özgecilik ve sosyal inovasyon değişkenlerine logaritmik ters dönüşüm yapılmasının ardından tekrar normallik testi yapılmıştır. Kolmogorov-Simirnov testi sonuçlarına göre, araştırma verileri normal dağılmaktadır $(\mathrm{p}=0,00)$. Tablo 3'de değişkenler arası ilişki ve yönü gösterilmiştir.

Tablo 3. Korelasyon Analizi

\begin{tabular}{|ccc|}
\hline Değişkenler & $(1)$ & $(2)$ \\
\hline Özgecilik (1) & 1 & $0,756^{* *}$ \\
\hline Sosyal İnovasyon (2) & $0,756^{* *}$ & 1 \\
${ }^{* *} p<.01$ & & \\
\hline
\end{tabular}

Tablo 3'de özgecilik ve sosyal inovasyon değişkeni arasında pozitif yönlü ve anlamlı ilişki mevcuttur $\left(\mathrm{r}=0,756^{* *} ; \mathrm{p}=0,00\right)$.

\subsubsection{Hipotezin Test Edilmesi}

Araştırmada geliştirilen hipotez $\left(\mathrm{H}_{1}\right)$, özgeci davranışın sosyal inovasyona etkisi test edilerek sınanmaktadır. Araştırmanın bağımsız değişkenin (özgeci davranış), bağımlı değişken (sosyal inovasyon) üzerindeki etkisinin ortaya çıkartılması amacıyla basit doğrusal regresyon analizi kullanılmış olup, sonuçlar Tablo 4'teki gibi tespit edilmiştir.

Tablo 4. Basit Regresyon Analizi

\begin{tabular}{|c|c|c|c|c|c|c|}
\hline Bağımsız değişken & Bağımlı değişken & $\beta$ & $\mathrm{SH}_{\beta}$ & $\beta$ & $\mathrm{t}$ & $\mathrm{p}$ \\
\hline Özgecilik & Sosyal inovasyon & 0,87 & 0,54 & 0,75 & 16,22 & 0,00 \\
\hline
\end{tabular}

$$
F=11,113 ; \Delta R^{2}=0,57 ; p=0,00
$$


Tablo 4'de çalışanların, özgeci davranışları ile sosyal inovasyon arasında kurulan basit doğrusal regresyon modelinin uygun olduğu ve özgeci davranışın, sosyal inovasyonun anlamlı bir tahmin edicisi olduğu tespit edilmişstir $(\mathrm{F}=11,113$; $\mathrm{p}<$.01). Modeldeki bağımsız değişken olan özgeci davranış, modelin bağımlı değişkeni olan sosyal inovasyonun \% 57 'sini açıklamaktadır. Regresyon katsayılarının anlamlılığına ilişkin t testi sonuçları incelendiğinde özgeci davranış, sosyal inovasyonu 0,75 beta değerinde pozitif ve anlamlı olarak etkilemektedir $(\beta=0,75 ; \mathrm{t}=16,22 ; \mathrm{p}<0,01)$. Dolayısıla $\mathrm{H}_{1}$ hipotezi kabul edilmiştir.

\section{Tartışma, Sonuç ve Öneri}

Ekonomik-sosyal koşullar ve tüketici ihtiyaçlarındaki hızlı değişim, işletmeleri daha inovatif ve rekabetçi hale getirmiştir. Yaşanılan gelişmelerin bir çoğu ekonomik ya da sosyal firsatlar sunmanın yanında sosyal sorunları da gündeme getirmektedir. Diğer yandan bireylerin öğrenim, paylaşım ve bilgi transferlerinin hızlanması, teknolojik ilerlemeler, sosyal ihtiyacı hızlandırarak (Hubert 2010) her alanda inovasyon ihtiyacını ortaya çıkarmıştır. Bu bağlamda ekonomik ve sosyal yapıyı oluşturan unsurlar da sürekli kendini yenilemek zorundadırlar. Teknolojik, sosyal ve kültürel alandaki değişimler, hem bazı problemleri beraberinde getirmekte hem de bu problemlere çözüm aramaktadır.

Sosyal inovasyon, toplumun büyük bir kesimi için mevcut durumun iyileştirilmesi ya da değişimi için eyleme geçmektir. Sosyal inovasyonun amacı, değişim ve dönüşüm için ortaya çıkan sorun ve ihtiyaçların giderilmesinde yenilikçi çözümler bulmaktır (Ateş 2018).

Sosyal inovasyon, insan ve toplum için sürdürülebilir bir yaşam sağlamak üzere yenilikçi çözümler üretmek ve uygulamaktır. Bu noktada karşılık beklemeden gönüllü bir davranış olan özgecilik (Campbell 1998), toplumsal bir yarar sağladığında sosyal inovasyon için anlam kazanır. Dibou’ya göre (2012) özgecilik bir motivasyon işi olup; kişi, yardım ettikçe motive olmakta ve daha fazla yardım projelerinde yer almaktadır.

$\mathrm{Bu}$ çalışmada, sosyal sorumluluk projelerine ağırlık verilen teknoloji -telekomunikasyon işletmelerinde özgeci davranışın, sosyal inovasyona etkisi araştırılmıştır. Araştırma sonuçlarına göre özgeci davranış, sosyal inovasyondaki değişimin \%57'sini açıklamaktadır. Araştırma verilerine uygulanan regresyon analizi sonucunda özgecilik, çalışanların sosyal inovasyon algıları ve eylemlerini 0,75 beta değerinde pozitif ve anlamlı olarak etkilemiştir $(\beta=0,75)$.

Araştırma sonuca göre sosyal inovasyona etki eden değişken, sadece özgecilik davranışına bağlanarak açıklanabilir mi? Farklı sektörlerde çalışanların, sosyal inovasyon algılarını etkileyen hangi değişkenler mevcuttur? Soruları tartışılmaya açıktır.

Araştırmanın sınırlı zaman ve maliyet ile yapılması ve tek sektör olan teknoloji alanında incelenmesi kısıtları oluşturmaktadır. Araştırmacılara farklı sektörlerde karşılaştırmalı analizler ile özgecilik, empati, öz saygı gibi faktörleri ekleyerek; ayrıca özgeciliğin genetik ya da sürekli öğrenme yoluyla kazanıldığı ayrımı literatürde yer aldığından çalışanların kişilik özellikleri de çalışmaya dâhil edilerek literatüre katkı sağlamaları önerilir. 
Pelenk, S., E. / Journal of Yasar University, 2019, 14 (Special Issue), 124-132

\section{KAYNAKÇA}

Akbaba, Sırrı. 1994. “Grupla Psikolojik Danışmanın Sosyal Psikolojik Bir Kavram Olan Özgecilik Üzerindeki Etkisi.” Yayımlanmamış Doktora Tezi, Atatürk Üniversitesi Sosyal Bilimler Enstitüsü, Erzurum.

Andreoni, James.1990. "Impure Altruism and Donations to Public Goods: A Theory of Warm-Glow Giving", The Economic Journal. 100: 464-477.

Ateş, Muradiye.2018. Türkiye'de Sosyal İnovasyon Uygulamaları ve Genç Nüfusun Potansiyeli. İstanbul: Seta Yayınları. Bandura, Albert, and David Mc Clelland. 1977. Social Learning Theory. Engelwood Cliffs, NJ: Prentice Hall.

Batson, Daniel. 2010. Empathy-Induced Altruistic Motivation. M. Mikulincer, and P. R. Shaver inside, Prosocial Motives, Emotions, and Behavior: The Better Angels of Our Nature. Washington: American Psychological Association.

Bilgin, Nuri. 1988. Sosyal Psikolojiye Giriş. Ege Üniversitesi Edebiyat Fakültesi Yayınları, İzmir.

British Council Report, Türkiye. 2019. “Türkiye'de Sosyal Girişimlerin Durumu”. June 6, 2019. https://www.british council.org.tr/programmes/education/social-enterprise-research (TED University Social Innovation Center).

Bulut, Cagri, Hakan Eren ve Duygu Seckin Halac.2013. "Social Innovation and Psychometric Analysis". Procedia-Social and Behavioral Sciences, 82: 122-130.

Campbell, Colin. 1998. "Institutional Analysis and the Role of Ideas in Political Economy". Theory and Society. 27 (3): 377-409

Caulier-Grice, Julie, Anna Davies, Robert Patrick, and Will Norman. 2012. "Defining Social Innovation. A Deliverable of the Project: The Theoratical, Empirical and Policy Foundations for Building Social Innovation in Europe". European Commission, 7th Framework Programme, Brussels: European Commission.

Choi, Nia, and Satyajit Majumbar. 2015. Social Innovation: Towards A Conceptualisation Tecnology and Innovation for Social Change. Majumdar, Satyajit, Guha, Samapti, Marakkath, Nadiya,eds.2015. India: Springer.

Chou, Kee Lee.1996. "The Rushton, Chrisjohn and Fekken Self-Report Altruism Scale: A Chinese Translation". Personality and Individual Differences, 21: 297-298.

Comte, Auguste.1986. Pozitivizmin İlmihali, İstanbul: Milli Eğitim Basımevi.

Çiftçi,Gamze Ebru, ve Alper Gürer (2019). “Özgecilik Davranişinin Bireysel Performans Üzerindeki Etkisinde Çalişan Sesliliğinin Araci Rolü”. Sosyal Bilimler Dergisi. 9 (17).

Dees, J. Gregory.2001. The Meanings of Social Entrepreneurship.Stanford: Stanford University.

Dibou, Tanja. 2012. “Thinking About Altruism". Studies of Changing Societies: Comparative and Interdisciplinary Focus, 2(4).

Fakouri, Carolyn, M. Ebrahim Fakouri, and B. Karl Zucker. 1991. "Empathy, Others-Concept and Prosocial Orientations" . Perceptual and Motor Skills 72, no.30 (June): 743-748.

Folger, Robert, Russell Cropanzano, and Jerald Greenberg. 2001. "Fairness Theory: Justice as Accountability". Advances in Organizational Justice. 1: 1-55.

Fowler, Alan. 2000. "NGDOs as a Moment in History: Beyond Aid to Social Entrepreneurship or Civic Innovation?" Third World Quarterly. 21(4): 637- 654.

Fowler, James, and Cindy D. Kam. 2007. "Beyond the Self: Social Identity, Altruism, and Political Participation”. The Journal of Politics. 69 (3): 813-827.

Freedman,Jonathan,David Sears, and J. Merril Carlsmith. 1976. Social Psychology.NC: Prenticehill.

Frey, Bruno, and Stephan Meier. 2004. "Social Comparisons and Pro-Social Behavior: Testing "Conditional Cooperation" in a Field Experiment". American Economic Review. 94(5): 1717-1722.

Glancey, Keith, and Ronald Mc Quaid. 2000. Entrepreneurial Economics. NewYork: St. Martin's Press.

Gustavo, Carlo, and Brandy A. Randall. 2002. "The Development of a Measure of Prosocial Behaviors for Late Adolescent". Journal of Youth and Adolescence 31, no.1 (February): 31-44.

Güler Kümbül, Burcu. 2008. "Sosyal Girişimciliği Etkileyen Faktörlerin Analizi”. Doktora Tezi. Dokuz Eylül Üniversitesi Sosyal Bilimler Enstitüsü Çalışma Ekonomisi ve Endüstri İlişkileri Anabilim Dalı, İzmir.

Harbaugh, William.1998. "What Do Donations Buy? A Model of Philanthropy Based on Prestige and Warm Glow". Journal of Public Economics. 67:269-284.

Haugh, Helen. 2005. “A Research Agenda for Social Entrepreneurship”. Social Enterprise Journal. 1(1): 1-12.

Hubert, Agnes. 2010. Empowering People, Driving Change: Social Innovation in the European Union. July 52019. http://ec.europa.eu/bepa/pdf/publications_pdf/social_innovation.pdf.

Jurik, Nancy, and Ramsi Bodin. 2014. "Social Responsibility and Altruism in Smalland Medium-Sized Innovative Businesses". The Journal of Sociology \& Social Welfare. 41(4).

Kasapoğlu,Figen. 2013. “İyilik Hali İle Özgecilik Arasındaki İlişkinin İncelenmesi”. Hikmet Yurdu Düşünce - Yorum Sosyal Bilimler Araştırma Dergisi. 7 (13): 271 - 288.

Keleş, Meltem, ve Yasemin Özkan (2018). “Çevreci Sivil Toplum Kuruluşu Çalişanlarinin Sosyal Sorumluluk ve Özgecilik Tutumlarinin İncelenmesi: Ankara İli Örneği”. Sinop Üniversitesi Sosyal Bilimler Dergisi, $2(1): 127$.

Kemal, Köksal, ve Gürsoy, Ali.2018."Özgecilik Ve Çalışan Performansı Arasındaki İlişki: Kamu Sektöründe Bir İnceleme”. Türkiye Sosyal Araştırmalar Dergisi. 22 (3): 783-796.

Klein, Juan, Jean Marc Fontan, Dennis Harrisson, and Benoit Levesque. 2012."The Quebec System of Social Innovation: A Focused Analysis on the Local Development Field”. Finisterra. 47(94): 9-28. 
Mair, Johanna, and Ignasi Martí. 2006. "Social Entrepreneurship Research: A Source of Explanation, Prediction and Delight". Journal of World Business. 41(1): 36-44.

Markman, Gideon, Robert A. Baron, and David B.Balkin. 2003. The Role of Regretful Thinking, Perseverence and SelfEfficacy in Venture Formation. Cognitive Approaches to Entrepreneurship Research: Advances in Entrepreneurship, Firm Emergence and Growth. CT: JAI Press.

McClelland, David C. 1967. The Achieving Society. New York: The Free Press.

Morrison, Zygon Nancy, Sally Severino. 2007. “Altruism: Toward a Psychobiospiritual Conceptualization”. Journal of Religion and Science, 41(1): 25-39.

Mussen, Paul Henry, and Nancy Eisenberg-Berg. 1977. Roots of Caring, Sharing and Helping: The Development of ProSocial Behavior in Children. Oxford, England: W. H. Freeman.

Öztürk, Mesude Canan. 2016. İletişimci Bakış Açısıyla Sosyal İnovasyon. Ankara: Detay Yayıncılık.

Penner, Louis. 1978. Social Psychology. New York: Oxford University Press.

Rushton, Philippe, Roland D. Chrisjohn, and G. Cynthia Fekken. 1981. "The Altruistic Personality and Self Report Altruism Scale". Person and Individual Differences, 2:293-302.

Schwartz, Barry. 1993. "Why Altruism is Impossible and Ubiquitous". The Social Service Review. 3: $314-343$.

Sorokin, Pitirim. 1948 .The Reconstruction of Humanity. Boston: Beacon Press.

Schumpeter, Joseph (1934). The Theory of Economic Development. NewYork: Taylor and Francis Group.

Taylor, Shelley E., Letitia Anne Peplau, ve David Sears. 2010. Sosyal Psikoloji. İstanbul: İmge Yayınları.

Thompson, John, Ann Lees, and Geoff Alvy. 2000. "Social Entrepreneurship - A New Look at the People and the Potential". Management Decision. 38(5): 328-338.

Walter, G. Stephan, and Krystina Finley. 1999. "The Role of Empathy in Improving Intergroup Relations". Journal of Social Issues 55, no. 4 (Winter): 729-748.

Yeşilkaya, Mukaddes, ve Yıldız, Tayfun. 2018. “Özgeci Davranış Ekseninde Sosyal İnovasyon Eğiliminin İncelenmesine Yönelik Bir Araştırma”. Girişimcilik İnovasyon ve Pazarlama Araştırmaları Dergisi, 2(4): 81-97.

Yıldırım, Musa, ve Pınar Topçuoğlu (2016). “Özgeciliğin Çeşitli Demografik Değişkenlerle İncelenmesi: Sakarya Örneği”. Sakarya Üniversitesi Ĕ̌itim Fakültesi Dergisi. (32): 40-53.

Yöntem, Mustafa Kemal, ve Tahsin İlhan (2013). "Benlik Kurguları ve Otantikliğin Özgecilik Üzerindeki Yordayıcı Gücünün İncelenmesi”. International Periodical For The Languages, Literature and History of Turkish or Turkic, 8(8): 2291-2302. 